\title{
A gestação eterna: um caso de patogenia da função materna
}

Henrique Lupiañez da CUNHA ${ }^{1}$

Daniel Sócrates de CASTRO²

\author{
Endereço: Rua Rio de Janeiro, 2039/202, Belo Horizonte, MG. \\ Telefone: (31) 8855-8068 \\ E-mail: lupianezhenrique@gmail.com \\ ${ }^{2}$ Universidade Federal de São Paulo, UNIAD. \\ Endereço: Rua Botucatu, 394, Vila Clementino, São Paulo, SP. \\ Telefone: (11) 8340-4235 \\ E-mail: danielsocrates@yahoo.com.br
}

${ }^{1}$ Departamento de Neurociências e Comportamento da Universidade Federal de Minas Gerais, UFMG.

Recebido em: 04/06/2012 - Aprovado em: 18/12/2012 - Disponibilizado em: 30/12/2012

\section{Resumo:}

O presente artigo reporta o caso de W. , jovem fustigado pela AIDS, pelo preconceito, pelo abuso sexual e pela doença mental. W. apresenta alucinações visuais e auditivas após receber diagnóstico de AIDS e é tratado com antipsicóticos após receber diagnóstico de Transtorno Mental Orgânico com Sintomas Psicóticos e, em seguida, com antidepressivos, após mudança de diagnóstico para Transtorno Depressivo Secundário a Quadro Orgânico. O caso mostra como é possível, com uma intervenção sob transferência, produzir efeitos terapêuticos eficazes que não precisam ser atribuídos à medicação. $\mathrm{O}$ fato de terem sido obtidos efeitos estabilizadores neste caso não significa, necessariamente, que o paciente não seja psicótico, mas que foi possível intervir na posição que ele ocupava na relação com o Outro, e em especial, com sua mãe. Essa se destaca no grupo familiar e revela-se, ao longo da evolução do caso, como importante fator que nutria os seus conflitos e sintomas. Assim, W. exagera, gesticula, seduz, quase implorando por uma intervenção que o ajude a livrar, como ele mesmo diz, seu corpo e sua mente, das amarras de uma gestação eterna.

Palavras-chave: AIDS, transferência, psicose.

\section{Eternal pregnancy: a case of maternal role pathogenesis}

\begin{abstract}
:
This article reports the case of W., a young man affected by AIDS, prejudice, by sexual abuse and mental illness. W. presents visual and auditory hallucinations after receiving a diagnosis of AIDS and is treated using antipsychotics after receiving a diagnosis of Organic Mental Disorder with Psychotic Symptoms and then with anti-depressants after a change in diagnosis for Organic Depressive Disorder. This case shows how it is possible, using transference, to achieve effective therapeutic effects that do not need to be attributed to any medication. The fact that stabilizing effects have been obtained in this case does not necessarily means that the patient is not psychotic, but that it was possible to intervene in the position he occupied in relation to the Other, and in particular with his mother. She stands out in the family and reveals itself along the course of the case, as an important factor that nurtured his conflicts and symptoms. Thus, W. exaggerates, gestures, lures, almost begging for an intervention to save him, as he says, your body and your mind, from the shackles of an eternal pregnancy.
\end{abstract}

Keywords: AIDS, transference, psychosis.

\section{Relato do Caso}

Identificação:

W.P.F., sexo masculino, 29 anos, natural e procedente de Belo Horizonte, solteiro, sem filhos, estudou até o $1^{\circ}$ ano do curso de Terapia Ocupacional, aposentado pelo INSS, espírita, vive com a mãe.
Queixa Principal:

"Sou psicótico e minha mãe é neurótica"

História da Moléstia Atual:

Em Janeiro de 2010, então com 28 anos, W., ao realizar rotineiramente exames laboratoriais, recebe o diagnóstico de AIDS. 77

Imediatamente, começa a apresentar humor 
deprimido, abandona a Faculdade, doa seus livros e roupas justificando que não precisará mais deles, uma vez que morreria em pouco tempo, torna-se agressivo em casa, chora durante a maior parte do dia, diminui o contato social, apresenta-se insone, "conversando sozinho durante a noite toda", começa a participar de um grupo de portadores de HIV, que o encaminha para acompanhamento psicoterápico, boicota o tratamento ambulatorial para controle da AIDS.

Em Março de 2010 o paciente é internado no Instituto Raul Soares (IRS) em Belo Horizonte por apresentar alucinações auditivas e visuais, humor deprimido e tentativa de autoextermínio ao ingerir benzodiazepínicos. É realizada toda propedêutica neurológica que se mostra sem alterações. A dose da medicação antirretroviral é reajustada e o quadro evolui para humor deprimido com ideação suicida.

No momento da avaliação psiquiátrica, apresentava risco importante de suicídio: "Tentei me matar duas vezes: na primeira, pulei num rio cheio de piranhas e nadei até me salvar... fiz isso por causa do Toninho, e, na segunda, tomei um tanto de remédio por não aguentar a pressão psicológica das cobranças da sociedade hipócrita. Se eu quiser um suicídio, ninguém me impedirá." Apresentava também relatos de alucinações visuais e auditivas: "Ouvia todos os vizinhos do meu prédio dizerem: bicha louca, escroto, babaca, rato de esgoto,
Clodovil, Roberta Close, Dona Beija, não vai trabalhar não?"; "Tem três fantasmas que aparecem para mim, eu vejo eles assim como eu vejo você. Uma delas fala pra mim: você representa muito bem o seu papel. Eu represento? O outro fica me perguntando: você já tirou a máscara?”.

Na ocasião da internação, o paciente encontrava-se com cuidado pessoal e de higiene precários, trajes sujos, consciência sem alteração de campo ou de nível, desorientado alopsiquicamente, no tempo e no espaço, normovigil, normotenaz, memória preservada, pensamento de curso lentificado, sem alterações de psicomotricidade, linguagem empobrecida, com alteração da consciência do eu.

O paciente é então internado por 60 dias, quando recebe o diagnóstico de Transtorno Mental Orgânico com Sintomas Psicóticos, iniciando tratamento com Haldol $5 \mathrm{mg} / \mathrm{dia}$ e Lorazepam $4 \mathrm{mg} / \mathrm{dia}$. Como as alucinações não apareciam de forma espontânea e não se mostraram consistentes, em cinco dias o diagnóstico foi alterado para Transtorno Depressivo Secundário a Quadro Orgânico (AIDS) e passou a ser medicado com Imipramina, em aumento progressivo até $150 \mathrm{mg} / \mathrm{dia}$ e Lorazepam $4 \mathrm{mg} /$ dia. Como o paciente voltou a relatar alucinações visuais e auditivas, iniciou-se a administração de Trifluoperazina ajustando-se a dose até $25 \mathrm{mg} /$ dia. O paciente recebe alta com remissão das alucinações e humor algo deprimido, sem ideação suicida. 
Em Junho/2010, o paciente inicia acompanhamento psiquiátrico ambulatorial, tendo sido tentada diminuição da Trifluoperazina por várias vezes, mas tendo que retornar à dose inicial uma vez que o paciente continuava relatando as alucinações. Como existia dificuldade de conseguir a medicação no Posto de Saúde, foi alterada para Haldol $5 \mathrm{mg} / \mathrm{dia}$.

Em Janeiro de 2011, o psiquiatra, durante o atendimento ambulatorial, nota que o uso da medicação é irregular, o relato das alucinações não é espontâneo e quando aparece é teatralizado. $\mathrm{O}$ paciente tem postura de vítima, com uso freqüente de hipérboles no seu discurso, supervalorizando suas queixas e seus sintomas. Nota-se também a presença constante da mãe, que monopolizava a consulta, não permitia que o paciente falasse ("Chega, W., você já falou muito, agora sai que quem vai conversar com o doutor sou eu!"), o humilhava durante o atendimento ("Ele não quer contar então eu vou falar, ele tá transando com homem de novo!"; "Depois que ele começou a sair com esse rapaz, eu estou lavando a roupa dele com desinfetante no tanquinho, porque eu não sei em que ele está se esfregando"), determinava a medicação a ser usada e o intervalo das consultas ("Doutor, quero que você dê para ele um remédio que tire a potência, porque eu não quero que ele transe mais."), queixava-se de todos os médicos anteriores do paciente, administrava ela própria a medicação diária do paciente, não permitia que o mesmo andasse sozinho pelas ruas, recusava-se a sair do consultório quando solicitada e, quando esse pedido era feito de forma mais ríspida, ela saía, esperava na porta, e continuava fazendo as mesmas exigências e colocações. Frequentemente trazia presentes e bilhetes para as consultas ou os enviava pelo filho.

Como em todos os registros do prontuário do paciente, as alucinações nunca se mostravam consistentes. Foi suspendido o antipsicótico, o que não resultou em nenhuma alteração do quadro até o mês seguinte, quando foi imposto para a mãe do paciente que ela não mais deveria comparecer ás consultas. O próprio paciente deveria administrar sua medicação e vir sozinho para o hospital, uma vez que o mesmo tinha plenas condições para tal. A mãe foi orientada também a iniciar um atendimento psicoterápico e foi encaminhada ao ambulatório de psicoterapia do IRS, onde tem sido atendida.

O paciente começou a apresentar então uma transferência erotizada, que foi contornada com a diminuição do tempo das consultas e espaçamento das mesmas, que eram semanais no momento.

Na consulta seguinte, o paciente já se mostrava diferente, com melhora do humor, retomando atividades no seu dia-a-dia, com planos para o futuro, sem relatos de alucinações, falando sobre assuntos importantes durante o atendimento, que, até então não haviam sido abordados. 
Continua até o momento sendo medicado apenas com Clorpromazina 25mg á noite.

História Social:

Infância

O paciente foi entregue para a avó aos três meses de idade porque a mãe "não sabia criar filho". Conta que foi abusado sexualmente por um "Pai-de-santo", que morava em sua casa e era namorado de sua tia, dos três aos 14 anos de idade: "Eu tocava nele e ele me tocava, ficava atrás de mim se esfregando e me chamando de viadinho."; "Eu gostava dele, aliás, hoje me arrependo de ter contado que ele me abusava, quem sabe se eu tivesse ficado calado, hoje eu não estava tão sozinho."

\section{História Ocupacional}

Nos quatro últimos anos, W. já ocupou as funções de: Office-boy, representante da Natura, representante da Avon e se interessou por outras profissões, tendo feito alguns cursos profissionalizantes para: cabeleireiro, tarólogo, cartomante, escritor e artista plástico.

\section{Relacionamentos}

O paciente já apresentou comportamento promíscuo, porém, desde o início da manifestação de sintomas da AIDS, o paciente tem mantido relacionamentos fugazes com parceiros fixos: "Já fui muito promíscuo, ficava na rua e transava debaixo dos viadutos, com mendigos, não tava nem aí, transava mesmo, mas agora não quero mais ser promíscuo. Quero alguém pra ter compromisso, algo sério."; "Se eu não arranjar um compromisso, um homem que me dê afeto, arrumo um gigolô."

\section{Família}

W. é filho único e não conheceu o pai, todas as referências que tem a seu respeito vem do discurso da mãe: "Meu pai é muito rico e famoso, mas eu nem conheci... o dia que minha mãe falou pra ele que eu tinha sido abusado, ele falou que era por causa da minha voz, que é de bicha."

Durante grande parte de sua vida, foi criado pela avó materna: "Minha avó que me criou, fazia tudo pra mim, mas me enchia o saco dizendo o que eu devia e não devia fazer."

Atualmente vive com a mãe, com a qual vive uma relação conturbada, com discussões e agressões verbais de ambas as partes. W. considera a mãe como a gênese de grande parte de seus problemas: "Minha mãe é uma bruxa."; "Minha mãe é neurótica."; "Eu odeio minha mãe."; "Às vezes, eu queria que minha mãe morresse e me deixasse em paz."; "Minha mãe me sufoca, me vigia, grita muito, é muito estressada."; "Eu quase fico louco quando minha mãe começa a falar."

\section{Sexualidade}

No início de seu acompanhamento, W. parecia não aceitar bem sua orientação sexual: "Sou um bissexual em potencial,"; "Quero largar o homossexualismo e viver como monge budista."; "Meu sonho é casar e ter filhos." 
Ao longo dos últimos dois anos, já em acompanhamento psicoterápico, ele mudou seu discurso: "Já resolvi: sou homossexual mesmo."; "Sou passivo."; "Sou bicha, mas não sou louca."; "Minha mãe fala que eu vivo no pecado, mas eu não vou deixar de ser homossexual por isso, não."

Hipótese Diagnóstica:

Eixo I: Esquizofrenia ou outros transtornos psicóticos

Eixo II: não se aplica

Eixo III: SIDA (B24)

Eixo IV: Problemas com o grupo primário de apoio

Problemas relacionados ao ambiente social

Problemas de moradia

Problemas econômicos

Eixo V: AGF (Avaliação Global do Funcionamento $)=60$.

\section{Discussão}

No caso de W., a figura materna destaca-se no grupo familiar e revelou-se, ao longo da evolução do caso, como importante fator que nutria os seus conflitos e sintomas.

Uma adequada maternagem - que Winnicott, denominava como sendo aquela provinda de uma mãe suficientemente boa alude ao fato de que essa mãe não frustra, nem gratifica de forma excessiva, o que possibilita um sadio crescimento do self do seu filho (Zimermam, 1999). Essa condição de maternagem requer uma série de atributos e funções da mãe, que tanto podem pautar por uma normalidade, como também podem adquirir características patogênicas.

As frustrações, além de inevitáveis, são indispensáveis ao crescimento emocional e cognitivo da criança. Entretanto, elas podem ser escassas, exageradas ou incoerentes. No caso de W., elas foram por demais escassas, tendo sua mãe tentado resolver todas as necessidades e desejos da criança, antecipando-se à capacidade de seu filho pensar para achar soluções para os problemas. Assim, ela não só inibiu no filho a capacidade para pensar, como também reforçou excessivamente sua onipotência e um vínculo simbiótico tão forte, que chega a ser o que Meltzer (1975) conceitua como "identificação adesiva" ("Esse menino não come, eu compro Danoninho, pico o bife no prato dele e ele nada de comer..."; "Eu que faço tudo pra ele, levo pra cortar cabelo, escolho a roupa, dou o remédio na boca, administro o dinheiro dele, faço a comida que ele gosta..."). Nos casos mais extremos, de acordo com MacDougall (citado em Rocha, 1996), ocorre o que ela denomina "um corpo para dois", em que a mãe pode obrigar a criança a sentir os mesmos sintomas e angústias corporais que ela, sendo comum, em muitos casos, a imposição que a criança compartilhe com ela roupas e medicamentos: "Queria que você passasse Rivotril pra ele, porque ele se dá muito bem com esse remédio, eu até dou do meu pra ele quando ele tá nervoso. Aliás você não podia me dar uma receita no meu nome, não?". 
A função de continência, como Bion a denomina, ou mesmo holding para Winnicott, que consiste em conter as cargas de identificações projetivas, é fundamental para a estruturação sadia da criança (Zimermam, 1999). Trata-se de um processo ativo da mãe em que ela "acolhe", "transforma" e "devolve" para o filho, devidamente desintoxicados, significados e nomeados, o "conteúdo" das identificações projetivas dele.

Na hipótese de que a mãe não consiga exercer essa função, a criança vê-se obrigada a incrementar o uso das identificações projetivas, num movimento de hipérbole, como um apelo desesperado para ser compreendido e contido. W. possui esse comportamento exagerado, supervalorizando suas queixas e seus sintomas.

O discurso materno é outra função importante. Através dele, a criança pode "tomar emprestado" significados da mãe e introjetá-lo. No caso de W., nota-se uma conotação de negativo e inferior quando se refere aos comentários da mãe a seu respeito: "Sou a ovelha negra da família"; "Era pra eu ser médico, mas nem isso eu consegui."; "Sou uma vergonha pra minha mãe".

Já a "função especular materna", é uma função na qual a criança se vê refletida e reconhecida no olhar da mãe e é de grande importância para o seu desenvolvimento. A mãe pode, nesse caso, tanto refletir o que a criança realmente é, ou, como aqueles espelhos côncavos e convexos dos parques de diversão, pode distorcer as imagens e refletir aquilo que ela própria é, ou imagina ser. A mãe de W. o nomeia de promíscuo e loucoque-usa-remédio, enquanto a mesma é dependente de benzodiazepínicos e foi abandonada pelo pai de $\mathrm{W}$. por este não ter certeza da paternidade, tamanho o número de parceiros sexuais que ela tinha na época.

A mãe de W. parece ter construído um projeto inconsciente de uma 'gestação eterna"'(Zimermam,1999). Ela é uma mãe deprimida, que demonstra medo de ficar sozinha e investiu em um vinculo simbiótico com o filho, cimentado em culpas, de modo a garantir o seu "seguro-solidão".

Já W., mesmo fustigado pela AIDS, pelo preconceito, pelo abuso sexual, pela doença mental, exagera, gesticula, seduz, quase implorando por uma intervenção que o ajude a livrar, como ele mesmo diz, seu corpo e sua mente, das amarras de uma gestação eterna.

W. apresentava alucinações auditivas bem características: ouvia os vizinhos do prédio insultá-lo. As alucinações fazem alusões a dois temas fundamentais em sua posição na vida: sua identificação sexuada e sua identificação como profissional: quem sou eu e o que sou? Os "fantasmas" que aparecem para ele o interrogam: "você representa bem o seu papel, já tirou a máscara?" E como se lhe faltasse, justamente, uma identidade, e poderíamos pensar que se trata de um sujeito histérico em busca de sua identidade. 
Ao contrário dos pacientes que não admitem sua homossexualidade, em W. as alucinações ocorrem em um sujeito que se reconhece como homossexual, porém em conflito sobretudo com sua mãe, que não aceita sua "escolha sexual". As alucinações retornam cada vez que os anti-psicóticos são reduzidos, e isso mesmo depois da estabilização do quadro orgânico. O paciente poderá prescindir dos anti-psicóticos quando uma outra operação tem lugar: uma operação realizada na transferência, que dá voz a ele nos atendimentos, impedindo que sua mãe fale por ele e que o deprecie no lugar e hora em que ele deve tomar a palavra. Silenciar a mãe ali, tanto quanto é possível, e oferecerlhe outro lugar para falar, separando W. do lugar de objeto que ocupava no discurso da mãe, tem como efeito silenciar as alucinações e permitir ao sujeito dizer o que é e o que quer.

O princípio, colocado por Freud e destacado por Lacan é que, aquilo que é abolido dentro retorna de fora como vindo do Outro. No caso de W., a invasão pelo Outro materno vai de par com a invasão pelas vozes. A separação operada no tratamento entre o sujeito e sua mãe, tem sido, portanto, terapêutica e nos permite pensar algo sobre a posição desse sujeito na estrutura familiar.

$$
\text { A esse respeito, Lacan }
$$

escreveu sobre duas posições possíveis para uma criança: ela pode ser um sintoma do par parental, ou ela pode ser objeto da fantasia da mãe. O primeiro caso pode ser mais complexo, pois tem a ver com o recalque, mas por isso mesmo é mais permeável à intervenção do psicanalista. No segundo caso, a criança pode ocupar uma posição mais fixa, submetida ao Outro materno: parece ser o que W. enuncia quando diz: "sou psicótico e minha mãe é neurótica". Essa fala poderia nos enganar, nos fazendo pensar em um sujeito histérico que se faz de louco, mas sua posição na relação com a mãe faz de fato pensar em uma estrutura psicótica. Senão, onde está o pai ou a função do Nome-do-pai neste caso? "Meu pai é muito rico e famoso, mas eu nem conheci"... "O dia que minha mãe falou prá ele que eu tinha sido abusado, ele falou que era por causa da minha voz, que é de bicha"... "Minha mãe tinha tantos namorados quando engravidou que o meu pai achou que não fosse dele"... Eis aí um pai "rico e famoso", que o paciente não conheceu e que não o reconheceu como filho, senão como "bicha".

Há, na história desse paciente, duas mães (a mãe e a avó) e dois pais (o desconhecido e o pai-de-santo). Em todas as relações, W. foi colocado numa posição de objeto: foi entregue para a avó aos três anos de idade porque a mãe não sabia criar filho. A avó fazia tudo para ele, inclusive dizer-lhe o que devia e não devia fazer. A mãe tinha muitos namorados, e, na mesma época em que foi pego pela avó, começou a ser abusado pelo pai-de-santo. Assim, dos três aos 14 anos, W. não teve um pai, mas um pai-desanto de quem gostava e que o fez de objeto sexual. W. alojou-se nesse lugar e saiu dele 
apenas para ser tratado como objeto por sua mãe.

O diagnóstico de AIDS foi a gota d'água que veio precipitá-lo também no lugar de objeto de cuidados médicos. A maneira submissa com que consente a essa posição de objeto manipulado ou falado pelo Outro parece ser um indicativo para o diagnóstico e orienta as intervenções do psicanalista, com bons resultados.

\section{Referências Bibliográficas}

1. Lacan, J. (2003). Nota sobre a criança, in Outros Escritos, Rio de Janeiro: Editora Zahar, (pp. 269-270).

2. Meltzer, D. (1975). Identificação adesiva. Jornal de Psicanálise, 38, (pp.40-52).

3. Rocha, F. (1996). A psicanálise e o paciente somatizante: Introdução às idéias de Joyce Macdougall. Revista Brasileira De Psicanálise, 30, (pp.4).

4. Zimerman, D. E. (1999).

Fundamentos Psicanalíticos. São Paulo: Editora Artes Médicas Sul Ltda, (pp.103-111). 